\title{
Assessment of intelligence quotient among schoolchildren of fishermen community of Kutch, Gujarat, India
}

\section{Kailash Asawa ${ }^{1}$, Piyush Pujara ${ }^{1}$, Jigar P. Thakkar ${ }^{2}$, Bindi Gajjar Pandya ${ }^{3}$, Anant Raghav Sharma ${ }^{4}$, Sonia Pareek ${ }^{5}$, Aniruddh Tak ${ }^{6}$, Mridula Tak ${ }^{1}$, Ronak Maniar ${ }^{7}$}

\author{
${ }^{1}$ Department of Public Health Dentistry, Pacific Dental College and Hospital, Udaipur, Rajasthan, India \\ ${ }^{2}$ GMERS Medical College and Hospital, Dharpur, Patan, Gujarat, India \\ ${ }^{3}$ Department of Oral Pathology and Microbiology, Karnavati School of Dentistry, Uvarsad, Gandhinagar, Gujarat, India \\ ${ }^{4}$ Department of Periodontics, Pacific Dental College and Hospital, Udaipur, Rajasthan, India \\ ${ }^{5}$ Department of Public Health Dentistry, Government Dental College and Hospital, Jaipur, Rajasthan, India \\ ${ }^{6}$ Department of Oral Pathology and Microbiology, Pacific Dental College and Hospital, Udaipur, Rajasthan, India \\ ${ }^{7}$ Department of Orthodontics, Pacific Dental College and Hospital, Udaipur, Rajasthan, India
}

\begin{abstract}
Background and aim: The aim of the study was to assess the intelligence quotient of fishermen schoolchildren of Kutch, Gujarat, India.

Materials and methods: A descriptive cross-sectional study was conducted among 8 to 10 years old schoolchildren living in Kutch District, Gujarat, India, from January to February 2013. Seguin Form Board Test was used to assess the intelligence quotient (IQ) level of children. Means of groups were compared by independent student $t$-test. Stepwise multiple linear regression was used to identify predictors for IQ. Results: The mean average timing taken by fishermen schoolchildren to complete the test was $30.64 \pm$ \pm 4.97 . Males had significantly lower mean timing scores than females $(p<0.05)$. Participants with severe dental fluorosis, low socio-economic status (SES), lower education level of both mother and father and those who were overweight had significantly higher mean timing scores for average category.

Conclusions: The present study suggested a low IQ among fishermen schoolchildren community of Kutch, Gujarat, India. The major factors which influenced their IQ were dental fluorosis, low SES, low education level of parents and high body mass index.
\end{abstract}

(Int Marit Health 2014; 65, 2: 73-78)

Key words: cross-sectional, fishermen, intelligence quotient, Kutch

\section{INTRODUCTION}

Intelligence has been defined in many different ways including, but not limited to, abstract thought, understanding, self-awareness, communication, reasoning, learning, having emotional knowledge, retaining, planning and problem solving. An intelligence quotient (IQ) is a score derived from one of several standardised tests designed to assess intelligence. IQ scores are used as predictors of educational achievement, special needs, job performance and income. There is considerable relationship between a person's degree of intelligence and range of activities, the level of achievement and the depth of understanding possible to him [1].

There are many factors that influence intellectual development; besides the major influence of a high fluoride environment, the occupation and education of the parents also appears to play a definite role [2].

Another key factor is socio-economic status (SES) of parents, since low intelligence in children is somewhat more frequent among low-income families, and poverty itself has a strong negative association with child's development. 
Research has showed that heritability of intelligence is greater in high SES families, because such families seem likely to provide more opportunities to realise differences in children's genetic potentials. Conversely, in lower SES families, genetic differences might be restrained by poverty. In other words, children of low SES may actually be genetically different from children of higher SES [3]. Research have also shown that a large number of children with low SES face instability in their lives [4].

Parent's presence at home, especially during early years of life, is essential in order to establish "attachment" between parent and child. Children who do not have adequate time with their parents are at risk of living a life feeling adrift, not connected in a positive relationship in a manner that lends itself to productive behaviour. These children are at risk of unproductive behaviour that could eventually be counter to their wellbeing and development leading, at worst, to self-destructive behaviours including social withdrawal, poor cognitive development, lower intelligence, truancy and delinquency [5]. Children's early experiences shape who they are and affect lifelong health and learning. To develop to their full potential, children need safe and stable housing, adequate and nutritious food, access to medical care, secure relationships with adult caregivers, nurturing and responsive parenting, and high-quality learning opportunities at home, in child care settings and in school [4].

Fishermen have prolonged hours of continuous work so they spent less time in childcare and looking after their children. This may cause the children to be less secure in relation to their fathers, less successful in school and to show less aptitude in intelligence tests.

Kutch is the largest District in India with a total area of $45,652 \mathrm{~km}^{2}$. Kutch has $400 \mathrm{~km}$ coastline that constitutes one-fourth of the Gujarat coastline and one-twentieth of India's coastline. The Kutch coast and fishing community are not well known in India. The relative remoteness of the Kutch coast and the low social, economic and political power of the fishing community have contributed to this state of affairs [6].

Since environmental factors related to health can lead to significant cognitive impairment, particularly if they occur during childhood when the brain is growing [1], and owing to the paucity of literature, the present study has been undertaken with an objective to assess the intelligence quotient of fishermen schoolchildren in the coastal region of Kutch, Gujarat, India.

\section{MATERIALS AND METHODS}

\section{STUDY DESIGN, SETTING AND POPULATION}

A descriptive cross-sectional study was conducted among 8 to 10 years old schoolchildren living in Kutch District, Gujarat, India, from January to February 2013.

\section{ETHICAL CONSIDERATIONS}

Before the beginning of the study, ethical approval was obtained from the ethical committee of Pacific Dental College, Udaipur. Official permission to examine the schoolchildren was obtained from the school authorities and written informed consent was obtained from parents of children who participated in the study.

\section{PILOT SURVEY}

A pilot study was carried out among 20 fishermen schoolchildren to determine the feasibility and practicability of the study and the time required for examination of each subject. Mean scores for average timing of fishermen children was found to be $30.23 \pm 10.12$. Based on the results of pilot study, $95 \%$ confidence level, $5 \%$ precision and $80 \%$ power of the study, final sample size calculated was 280 .

\section{SAMPLE SELECTION}

Prior to instigation of the study, list of all villages in the Kutch District was obtained from municipality of Kutch.

Multi-stage random sampling was employed to select the study population. Four zones of the Kutch coast are divided as follows.

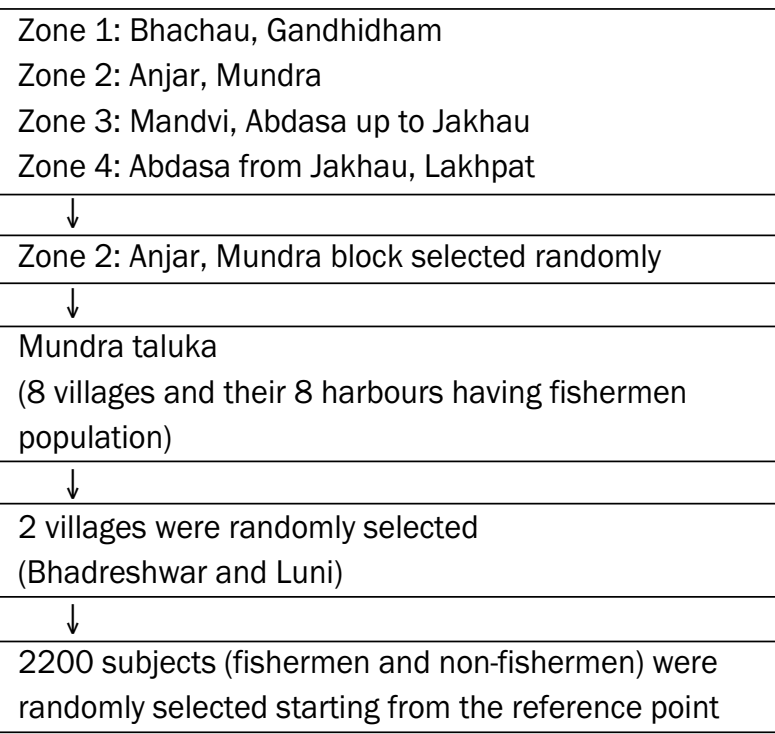

Final sample comprised 304 fishermen schoolchildren.

\section{INCLUSION AND EXCLUSION CRITERIA}

Inclusion criteria fulfilled the children who were born and brought up in the study areas. Exclusion criteria included genetic, congenital or acquired diseases related to nervous systems in the past or at present.

\section{PRO FORMA DETAILS}

The proforma consisted of 3 sections: (1) General information; (2) Dean's fluorosis index; (3) Body mass index (BMI).

General information consisted of demographic data including name, age, gender, date of birth, parental education, 
SES and family size. SES was measured using Prasad's scale [7] and categorised into low, medium and high.

Body weight was recorded to the nearest 100-g using a standard beam balance scale with the subject barefoot and wearing light clothes. The balance was calibrated at the beginning of each working day and at frequent intervals throughout the day. Body height was recorded to the nearest $0.5 \mathrm{~cm}$ according to the following protocol: no shoes, heels together and head touching the ruler with line of sight aligned horizontally. To avoid subjective errors, all the measurements were done by the same person and by one recording assistant.

BMI was calculated using the formula [8]: Weight [kg]/ $/$ Height $^{2}[\mathrm{~m}]$. Respondents were categorised into 4 levels: underweight $\left(\mathrm{BMI}<18.5 \mathrm{~kg} / \mathrm{m}^{2}\right)$, normal $(18.5<\mathrm{BMI}$ $\left.<24.5 \mathrm{~kg} / \mathrm{m}^{2}\right)$, overweight $\left(25<\mathrm{BMl}<29.5 \mathrm{~kg} / \mathrm{m}^{2}\right)$ and obese $\left(\mathrm{BMl}>30 \mathrm{~kg} / \mathrm{m}^{2}\right)$.

Fluorosis was measured according to World Health Organisation guidelines (1997) [9] with the help of Dean's fluorosis index.

\section{STUDY INSTRUMENT}

IQ was tested using Seguin Form Board (SFB) Test to assess visual discrimination, matching and eye-hand coordination. Test materials consisted of ten differently shaped wooden blocks and a large form board with recesses corresponding to these shapes [10]. The testing was administered individually to each child, in compliance with the guidelines and direction of the SFB test manual. Retesting was done on 10 children after a day so as to check the reliability of the testing protocol (Kappa $=0.8$ ).

\section{METHODOLOGY}

On the pre decided days, the investigator visited the schools. With the help of school authorities a class room was arranged. Children were made to sit in the classroom. IQ testing kit was placed on the table and children were asked to come one by one and perform the test. While administering the test, these blocks were taken out by the examiner and stacked in front of the subject who had to put them back as quickly as he/she could. The following instructions were given to the students: "Here are ten wooden blocks which have to be put by you in the appropriate space. Be as fast as you can. You will be allowed only three trials." Prior to starting the test proper, a 'ready' signal was given and at the second signal 'start', child started placing the wooden blocks. The timing with stop watch was matched with the child picking up the first block. The task was repeated 3 times. Time, in seconds was obtained for each trial by investigator, who seated beside and slightly to the back of the subject to be tested. The total time score of each subject in 3 trials, their average and the shortest time score were obtained.

\section{STATISTICAL ANALYSIS}

The data was coded and entered into Microsoft Excel spreadsheet. Analysis was done using Statistical package for social science (SPSS) version 15 (SPSS Inc. Chicago, IL, USA) Windows software program. The variables were assessed for normality using the Kolmogorov-Smirnov test. Descriptive statistics were calculated. Means of groups were compared by independent student $t$-test. Stepwise multiple linear regression was used to identify predictors for IQ. Level of significance was set at $p \leq 0.05$.

\section{RESULTS}

Table 1 shows the distribution of study subjects by gender, SES, education level of parents, number of person in family, Dean's fluorosis index and BMI. Among all subjects there were 160 (52.6\%) males and 144 (47.4\%) females. Most of the participants belonged to low socio-economic group (52\%) and parental education was up to middle level $(n=220)$. Majority of participants had severe dental fluorosis (30.6\%) and had normal BMI (31.3\%).

Table 2 shows the mean scores for average, shortest and total timing category among fishermen schoolchildren which was found $30.64 \pm 4.97,29.10 \pm 5.37$ and $91.98 \pm 14.99$, respectively.

Table 3 illustrates association of mean scores for average timing with various independent variables. It was observed that males had lower mean timing scores than females and difference was statistically significant $(p<0.05)$. Participants with low SES and primary education level of both mother and father had significantly higher mean timing scores for average category $(p<0.05)$. Similarly, participants with severe dental fluorosis and those who were overweight also had significantly higher mean timing scores for average category $(p<0.05)$.

Table 4 represents stepwise multiple linear regression analysis with mean IQ for average timing as the dependent variables and various independent variables in study group. The best predictors in the descending order for mean IQ were dental fluorosis, SES, educational status and BMI with variances of $1.6 \%, 2.8 \%, 4.9 \%$ and $6.6 \%$, respectively.

\section{DISCUSSION}

The present study was undertaken with an objective to assess the intelligence quotient of fishermen schoolchildren in the coastal region of Kutch, Gujarat, India. IQ has been used to measure intellectual ability for almost 100 years, and there are many standards of measuring IQ [2]. In the present study investigators have used SFB Test which finds application in assessment of general intelligence of children in pre-primary and primary school years [11] or for measuring visual discrimination and matching, eye-hand coordination and cognitive-perceptual abilities in children [12]. 
Table 1. Distribution of study population by various independent variables

\begin{tabular}{|c|c|c|}
\hline Variables & $\mathbf{N}$ & Percentage (\%) \\
\hline \multicolumn{3}{|l|}{ Gender } \\
\hline Male & 160 & 52.6 \\
\hline Female & 144 & 47.4 \\
\hline \multicolumn{3}{|l|}{ Socio-economic status } \\
\hline Low & 158 & 52 \\
\hline Medium & 111 & 36.5 \\
\hline High & 35 & 11.5 \\
\hline \multicolumn{3}{|l|}{ Education level } \\
\hline \multicolumn{3}{|l|}{ Mother } \\
\hline Up to primary level & 210 & 69.1 \\
\hline Up to middle level & 94 & 30.9 \\
\hline \multicolumn{3}{|l|}{ Father } \\
\hline Up to primary level & 196 & 64.5 \\
\hline Up to middle level & 108 & 35.5 \\
\hline \multicolumn{3}{|l|}{ No. of person in family } \\
\hline 3 & 36 & 11.8 \\
\hline 4 & 99 & 32.6 \\
\hline 5 & 97 & 31.9 \\
\hline 6 & 49 & 16.1 \\
\hline 7 & 23 & 7.6 \\
\hline \multicolumn{3}{|l|}{ Dean's fluorosis index } \\
\hline Normal & 30 & 9.9 \\
\hline Questionable & 13 & 4.3 \\
\hline Very mild & 30 & 9.9 \\
\hline Mild & 72 & 23.7 \\
\hline Moderate & 65 & 21.4 \\
\hline Severe & 93 & 30.6 \\
\hline Excluded & 1 & 0.3 \\
\hline Total & 304 & 100 \\
\hline \multicolumn{3}{|l|}{ Body mass index } \\
\hline Underweight & 52 & 17.1 \\
\hline Normal & 95 & 31.3 \\
\hline Overweight & 83 & 27.3 \\
\hline Obese & 74 & 24.3 \\
\hline
\end{tabular}

Table 2. Mean scores for average, shortest and total timing category among fishermen schoolchildren

\begin{tabular}{ll}
\hline Timing & Mean \pm standard deviation \\
\hline Average & $30.64 \pm 4.97$ \\
Shortest & $29.10 \pm 5.37$ \\
Total & $91.98 \pm 14.99$
\end{tabular}

Results of the present study showed that mean scores for average time, shortest time and total time taken to complete the test among fishermen schoolchildren were
Table 3. Association of mean scores for average timing with various independent variables

\begin{tabular}{|c|c|c|}
\hline Variables & Mean \pm SD & $\mathbf{P}$ \\
\hline \multicolumn{3}{|l|}{ Gender } \\
\hline Male & $21.90 \pm 6.15$ & \multirow{2}{*}{$0.03 *$} \\
\hline Female & $24.08 \pm 6.91$ & \\
\hline \multicolumn{3}{|l|}{ Socio-economic status } \\
\hline Low & $29.47 \pm 5.22$ & \multirow{3}{*}{$0.04 *$} \\
\hline Medium & $27.09 \pm 6.90$ & \\
\hline High & $27.01 \pm 6.53$ & \\
\hline \multicolumn{3}{|l|}{ Education level } \\
\hline \multicolumn{3}{|l|}{ Mother } \\
\hline Up to primary level & $28.98 \pm 5.11$ & \multirow[t]{2}{*}{$0.01 *$} \\
\hline Up to middle level & $27.22 \pm 6.70$ & \\
\hline \multicolumn{3}{|l|}{ Father } \\
\hline Up to primary level & $29.87 \pm 7.23$ & \multirow[t]{2}{*}{$0.002^{*}$} \\
\hline Up to middle level & $27.45 \pm 5.67$ & \\
\hline \multicolumn{3}{|l|}{ Dean's fluorosis index } \\
\hline Normal & $27.30 \pm 7.39$ & \multirow{7}{*}{$0.001^{*}$} \\
\hline Questionable & $28.69 \pm 6.04$ & \\
\hline Very mild & $27.35 \pm 6.18$ & \\
\hline Mild & $25.75 \pm 6.66$ & \\
\hline Moderate & $27.16 \pm 6.28$ & \\
\hline Severe & $29.56 \pm 6.67$ & \\
\hline Excluded & $24.33 \pm 1.23$ & \\
\hline \multicolumn{3}{|l|}{ Body mass index } \\
\hline Underweight & $27.21 \pm 7.39$ & \multirow{4}{*}{$0.05 *$} \\
\hline Normal & $27.89 \pm 5.62$ & \\
\hline Overweight & $28.65 \pm 6.39$ & \\
\hline Obese & $27.33 \pm 6.62$ & \\
\hline
\end{tabular}

Test applied: One way ANOVA, t-test, * $p \leq 0.05$ statistically significant; SD - standard deviation

Table 4. Stepwise multiple linear regression analysis with mean IQ for average timing as a dependent variable

\begin{tabular}{lllll}
\hline Model & $\mathbf{R}$ & $\mathbf{R}^{2}$ & $\mathbf{F}$ & $\mathbf{P}$ \\
\hline 1 & $0.122(\mathrm{a})$ & 0.016 & 9.86 & $0.000(\mathrm{a})$ \\
2 & $0.168(\mathrm{~b})$ & 0.028 & 8.75 & $0.000(\mathrm{~b})$ \\
3 & 0.221 (c) & 0.049 & 7.72 & $0.000(\mathrm{c})$ \\
4 & 0.258 (d) & 0.066 & 7.12 & $0.000(\mathrm{~d})$
\end{tabular}

a - predictors: (constant), fluorosis; $b$ - predictors: (constant), fluorosis, socio-economic status; $\mathrm{c}$ - predictors: (constant), fluorosis, socio-economic status, educational status; $d$ - predictors: (constant), fluorosis, socio-economic status, educational status, body mass index

$30.64 \pm 4.97,29.10 \pm 5.37$ and $91.98 \pm 14.99$, respectively. The speed of performance of fishermen schoolchildren was found to be slower when compared to findings suggested by Bharatraj [13] and Venkatesan et al. [14]. These findings may be due to exposure of fishermen children to 
high fluoride environment [15] and inadequate attention of parents because of their occupation. Participants with low SES and lower education level of parents had significantly higher mean timing scores for average category $(p<0.05)$. This finding was comparable with results of Yongxiang et al. [16] who revealed that the IQs of children born into an "employed" household was higher than those born into a farming household, and that the IQ levels of the children increased along with the education level of their parents. This indicates that a positive educational influence from the family is beneficial for intellectual development of a child. The positive link between SES and children's achievement is also established by Sirin [17] and McLoyd [18] and seminal literature reviews also have documented well the relation of poverty and low SES to a range of negative child outcomes, including low IQ, educational attainment and achievement, and social-emotional problems.

An analysis of performance on the SFB based on gender variable indicated that boys had faster and better performance than girls of same age levels $(p<0.001)$ which was accordance with observations reported by Douglas and Rushton [19]. This gender difference may be due to larger averaged brain size in males than in females, even after adjusting for body size [18].

In the present study overweight participants had significantly higher mean timing scores compared to other participants $(p<0.05)$, which was in accordance with studies conducted by Yu et al [20]. Two streams of research have given rise to the hypothesis that obesity can harm the brain and compromise performance on intelligence tests. The first stream of research comprises brain imaging studies that document structural and functional abnormalities in obese individuals that are apparent as early as in adolescence [21-24] and studies that show that obese children and adults have lower intelligence quotients than do lean controls $[25,26]$. In the present study majority of the participants were in moderate and severe dental fluorosis category which showed a significant relationship with intelligence quotient. These results are consistent with findings reported by Xiang et al. [27], Bloylock [28] and Tang et al. [2].

The predictors for Intelligence quotient as identified by stepwise linear regression were dental fluorosis, SES, educational status, BMI. Fluorosis was found to be the best predictor for IQ, which may be attributed to the fact that high levels of fluoride absorbed in the blood forms lipid soluble complexes which cross the blood-brain barrier and accumulate in cerebral tissues. The penetrated fluoride complexes adversely affect the central nervous system (CNS) development by different neurotoxic and excitotoxic mechanisms, such as free radical generation, inhibition of anti-oxidant and mitochondrial energy enzymes and inhibition of glutamate transporters [28]. The structural and functional alterations in CNS, specifically in the foetal period and the first 8 years of life, may lead to learning and intellectual deficits and cognitive dysfunctions. In addition, fluoride interferes with the activity of the thyroid gland, which has a deleterious effect on brain development and function in children [29].

One of the limitations of this study was that SFB test may not give us a complete picture of mental development. It must be supplemented by other comprehensive tests such as Stanford-Binet or Wechsler Intelligence Scale. Apart from these shortcomings, other factors like emotional tension, anxiety, and unfamiliarity with the testing process might also have greatly affected test performances.

IQ is known to be influenced by many factors including differences in biological susceptibility, environmental conditions, and measurement errors. Variables like nutrition, prenatal care, breast feeding, stimulating environment, parental IQ, endemic iodine deficiency, freedom from disease, physical trauma, good schooling, and maternal exposure to fluoride during pregnancy plays a large role in determining IQ development. Further research is required involving longitudinal study on the same target population to clarify the nature of the relationship between intelligence and these factors are clearly desirable.

\section{CONCLUSIONS}

The present study suggested a low IQ among fishermen schoolchildren community of Kutch, Gujarat, India. The major factors which influenced their IQ were dental fluorosis, low SES, low education level of parents and high BMI. However, other factors that might affect children's IQ need to be considered as well, and further studies are therefore needed to confirm the present findings.

\section{ACKNOWLEDGEMENTS}

The authors would like to thank the study participants for their participation and kind cooperation throughout the study.

\section{REFERENCES}

1. Intelligence quotient. Available at: http://en.wikipedia.org/wiki/ Intelligence_quotient. [Accessed on 05-09-2012].

2. Tang Q, Q Du J, Ma HH, Jianq SJ, Zhou XJ. Fluoride and children's intelligence: a meta-analysis. Biol Trace Elem Res 2008; 126: 115-120.

3. Turkheimer E, Haley A, Waldron M, D'Onofrio, B, Gottesman I. I. Socioeconomic status modifies heritability of IQ in young children. Psychol Sci 2003; 14: 623-628.

4. Sandstrom $\mathrm{H}$, Huerta $\mathrm{S}$. The negative effect on instability on child development: a research synthesis. Urban Institute 2013.

5. Working parents and child development. Available at: http://www. yoursocialworker.com/p-articles/working-parents.pdf: [Accessed on 12th April 2013].

6. Gulf of Kutch. Available at: http://en.wikipedia.org/wiki/Gulf_of_ Kutch. [Accessed on 25-04-2013]. 
7. Calculating BMI. Available at http://www.education.vic.gov.au/Documents/childood/professional/support/summery2.pdf. [Accessed on 05-04-2013].

8. Sharma R. Revision of Prasad's social classification and provision of an online tool for real-time updating. South Asian J Cancer 2013; 2:157.

9. World Health Organization. Oral health surveys. Basic methods. $4^{\text {th }} \mathrm{Ed}$. WHO, Geneva 1997, 36-51.

10. Basavarajappa D, Venkatesan S, Vidya M. Normative Data on Seguin Form Board Test. Indian J Clin Psychology 2009; 35: 93-97.

11. Spearman CE. The abilities of man: their nature and measurement. Macmillan, New York 1927.

12. David RL, Virginia CS. Seguin Form Board; Technical Report 20. Disadvantaged Children and their first School Experiences. EST Head Start longitudinal study. Technical Report Series ED081833.1972.

13. Bharatraj J. AllSH Norms on Seguin Form Board with Indian children. J All India Institute Speech Hearing 1971; 2: 117-127.

14. Venkatesan S, Basarvajappa D, Divya M. Seguin Form Board Test. Field try out on a modified procedure of test administration. Indian J Applied Psychology 2007; 44: 1-5.

15. Water and Sanitation Management Organization, Gujarat. Available at: www.wasmo.org. [Accessed on 07-04-2013].

16. Yongxiang $\mathrm{C}$, Fanlin $\mathrm{H}$, Zhenlong Z, Huiqin Z, Xisheng J. Research on the Intellectual Development of Children in High Fluoride Areas. Chin J Control Endemic Dis 1991; 6 (suppl.): 99-100.

17. Sirin SR. Socioeconomic status and academic achievement: a meta-analytic review of research. Rev Educational Res 2005; 75: 415-453.

18. McLoyd VC. Socialization and development in a changing economy: The effects of paternal job and income loss on children. Am Psychologist 1989; 44: 293-302.
19. Douglas NJ, Rushton JP. Males have greater g: sex differences in general mental ability from 100,00017 - to 18 -year-olds on the Scholastic Assessment Test. Intelligence 2006; 34: 479-486.

20. Yu ZB, Han SP, Cao XG, Guo XR. Intelligence in relation to obesity: a systematic review and meta-analysis. Obes Rev 2010; 11: 656-670.

21. Convit A. Obesity is associated with structural and functional brain abnormalities: where do we go from here? Psychosom Med 2012; 74: 673-674.

22. Yau PL, Castro MG, Tagani A, Tsui WH, Convit A. Obesity and metabolic syndrome and functional and structural brain impairments in adolescence. Pediatrics 2012; 130: e856-e864.

23. Mueller K, Sacher J, Arelin $\mathrm{K}$ et al. Overweight and obesity are associated with neuronal injury in the human cerebellum and hippocampus in young adults: a combined MRI, serum marker and gene expression study. TransI Psychiatry 2012; 2: e200.

24. Taki Y, Kinomura S, Sato $\mathrm{K}$ et al. Relationship between body mass index and gray matter volume in 1,428 healthy individuals. Obesity (Silver Spring) 2008; 16: 119-124.

25. Miller J, Kranzler J, Liu Y et al. Neurocognitive findings in Prader-Willi syndrome and early-onset morbid obesity. J Pediatr 2006; 149: 192-198.

26. Cournot M, Marquié JC, Ansiau D et al. Relation between body mass index and cognitive function in healthy middle-aged men and women. Neurology 2006; 67:1208-1214.

27. Xiang $Q$, Liang $Y$, Chen $L C$ et al. Effect of fluoride in drinking water on children's intelligence. Fluoride 2003; 36: 84-94.

28. Bloylock RL. Excitotoxicity: a possible central mechanism in flouride neurotoxicity. Fluoride 2004; 37: 301-314.

29. Susheela AK, Bhatnagar M, Vig K, Mondal NK. Excess fluoride ingestion and thyroid hormone derangements in children living in Delhi, India. Fluoride 2005; 38: 98-108. 